\title{
Towards Realising SDGs in the University of Helsinki
}

\section{Korhonen-Kurki, Kaisa}

Springer

2019-09-15

Korhonen-Kurki , K, Koivuranta , R , Kuitto , V M H , Pietikäinen , J , Schönach , P \& Soini , K 2019 , Towards Realising SDGs in the University of Helsinki . in G Nhamo \& V Mjimba (eds) , Sustainable Development Goals and Institutions of Higher Education . vol. 2020 , Sustainable Development Goals Series , Springer , Cham , pp. 15-29 . https://doi.org/10.1007/978-3-030-26157-3_2

http://hdl.handle.net/10138/333874

https://doi.org/10.1007/978-3-030-26157-3_2

unspecified

acceptedVersion

Downloaded from Helda, University of Helsinki institutional repository.

This is an electronic reprint of the original article.

This reprint may differ from the original in pagination and typographic detail.

Please cite the original version. 


\title{
Towards realising SDGs in the University of Helsinki
}

\author{
Korhonen-Kurki, Kaisa; Koivuranta, Riina; Kuitto, Virpi, Pietikäinen, Janna; \\ Schönach, Paula; Soini, Katriina
}

Kaisa Korhonen- Kurki, adjunct professor, research coordinator, University of Helsinki (corresponding author)

kaisa.korhonen@helsinki.fi

Yliopistonkatu 3, Helsus Hub

University of Helsinki, 00014

Finland

Riina Koivuranta, project coordinator

University of Helsinki

Virpi Kuitto, environmental specialist

University of Helsinki

Janna Pietikäinen, vice-dean, university lecturer

University of Helsinki

Paula Schönach, adjunct professor, research coordinator, University of Helsinki

Katriina Soini, adjunct professor, senior researcher

Natural Resources Institute Finland, Luke

\begin{abstract}
Universities, such as the University of Helsinki, are facing a growing trend to redefine their strategies and organisations along the lines of sustainability. However, the process of building the structures for sustainability research and education requires the breaking down of existing disciplinary silos. In this chapter we analyse the new initiatives in research, education and governance, and management operations to which the University committed during 2015-2018 through the lens of SDGs. We also explore the factors that enable or hinder sustainability transition at a university. The results of the SDG mapping show that SDG 4 (Quality Education) is an overarching goal represented in all new initiatives within research, education and university management. SDG 17 (Partnerships) and SDG 3 (Health and Wellbeing) are also equally strongly emphasised. However, SDGs 1 (No Poverty), 6 (Clean Water and Sanitation) and 5 (Gender Equality) are not considered, or if so, given little emphasis. Our analyses revealed that small niche innovations, tactical and operational activities at the grassroots level - networks, science activism and student awareness - pushed for regime-level changes. However, the financial incentives and policy changes initiated on the regime level enabled the niche-level innovations to develop and led to strategic decisions providing a window of opportunity to initiate structural changes.
\end{abstract}


Keywords: university transition, higher education, university sustainability, organisational culture, sustainable-development goals

\section{Introduction}

Our aim in this chapter is to explore the transition to sustainability in the University of Helsinki. In particular, we assess how far the university's new initiatives in research, education and operational management correspond with SDGs. We take a multi-level perspective on the socio-technological transition framework (Geels 2002; Geels and Schot 2007), and examine niche-level activities in the University of Helsinki so as to enhance understanding of how regime-level processes, particularly at the university but also in the wider context of Finnish science policy, have enabled/disabled their emergence. We demonstrate that the transition was supported by several internal and external factors and processes related to the evolution of sustainability science, research profiling and educational reforms. These on-going and partly overlapping processes created windows of opportunity that facilitated the onset of a transition that was based on the emergent science of sustainability. We show that all these processes are interconnected, and we conclude that both the positive push of external funding and strong internal support contributed to the transition to cross-disciplinary sustainability in the university.

Institutes of higher education are experiencing a growing need to redefine their activities, strategies and organisations along the lines of sustainability (Beynaghi et al. 2016; FerrerBalas et al. 2010). Indeed, sustainability is among the key topics in education, research, outreach and campus operations within universities (Barth and Michelsen 2013; FerrerBalas et al. 2009). Hundreds of them have joined networks related to sustainability, such as the Sustainable Development Solutions Network supported by the United Nations (UN) and the International Sustainable Campus Network (ISCN). A number of university-based centres or institutes focusing on sustainability research and education have been established (Lozano et al. 2015). Universities have started to implement SDGs in their internal operations, as well as in cross-sectoral partnerships with governments and communities to promote and support their adoption in society at large (Findler et al. 2018). All these activities could be seen as a response to the "sustainability call" put out in recent international (e.g. the SDG and Paris Climate Agreement 2015) and national conventions, as well as to real global environmental and social challenges (e.g. climate change, biodiversity loss and immigration). They are further reflected in the growing body of research that is documenting and monitoring progress.

However, despite the advances and successful practices, many studies also highlight various internal and external challenges and constraints in the transition to sustainability in universities (see e.g. Beringer \& Adomssent 2008; Beynaghi et al. 2016; Dedeurwaerdere 2013; Ferrer-Balas et al. 2008, 2009; Trencher et al. 2014a,b; AlbaredaTiana 2018). The nature and relative importance of these challenges and constraints may 
vary between countries and institutions, but there are some common characteristics, which we summarise as scientific, organisational, supportive, conceptual and ideological (see Soini et al. 2018). First, sustainability research and education are distinct from monodisciplinary research and education, requiring a paradigm shift on both the individual and the collective level towards systems thinking and interdisciplinary collaboration in research and education. Second, the organisational structure of universities has tended to support disciplinary-based research and education, hence new structures and practices are required to cross disciplinary boundaries and to increase the feasibility of research collaboration with non-academic partners. Third, current reward and funding systems within academia do not necessarily support inter- or trans-disciplinary sustainability research and education. Fourth, the conceptual vagueness of sustainability, along with the varying and conflicting aims and goals related to it, may cause problems in collaboration and communication across sectors and disciplines. Finally, although most parties agree on the need for sustainability in broad terms, there may well be differing views on how to achieve it.

Despite these challenges, research has also revealed many drivers that could enable the transition (Holmberg \& Samulesson 2006; Ferrer-Balaz et al. 2008). These include visionary leadership, combined with arrangements that promote cooperation and collaborative efforts among existing networks of people (e.g. interdisciplinary research groups) that operate across the university. These 'connectors', as well as units and practices that facilitate communication and the coordination of activities and responsibilities between disciplines and sectors may support the transition, and external pressure (from society or peer institutes) and funding may push it further.

There are numerous ways of analysing the barriers to sustainability in universities, as well as the enabling factors and the pathways of transition or transformation. Ferrer-Balas et al. (2008) introduced the Framework-Level-Actors framework when comparing the transition to sustainability in seven universities. The multi-level perspective on transition (MLP) and the transition-management (TM) framework that draws on organisational and management studies have also been found useful for analysing the transition process (Stephen \& Graham 2010). Transitions are understood in the latter as long-term and fundamental transformation processes through which established socio-technical systems shift to new and more sustainable modes.

First, we briefly describe our approach and our method. Second, we analyse some of the key documents reflecting the transition to sustainability in light of the SDGs. Third, we explore the hindering and enabling factors and fourth, we summarise the key issues that emerged from the analysis. 


\section{The transition to sustainability}

In line with Stephen and Graham (2010), who applied frameworks concerning sociotechnical transition and transition management in the context of the transition to sustainability in universities, we suggest that there are initiatives (such as sustainability centres and interdisciplinary Master's programmes on sustainability) that could be considered niche-level innovations in attempts to create amenable scientific and organisational conditions for inter- and trans-disciplinary sustainability research and education. Most of these innovations are developed on the niche level by small networks of dedicated actors, driven by internal momentum in the form of learning, performance improvement and support from powerful groups, and often constrained by time, space and scope (Bulkeley and Broto 2012). Experimentation on this level is triggered by the intentional destabilisation of existing institutions and routines as the actors seek novel opportunities and outcomes through informed deliberation.

The evolution of innovations is influenced by the socio-technical landscape, in other words the wider socio-political context from market to national and international policy, and from demography to technology. Destabilisation of the regime due to pressure in the landscape (for example, and in the case of universities new societal requests for science or funding availability) may create windows of opportunity for niche innovations.

The Transition Management framework adds four types of activity within the evolution of a transition: strategic, tactical, operational and reflexive (Loorbach 2007, see also Graham \& Stephen 2010). Strategic activity focuses on high-level engagement in visioning, laying out long-term system-level goals and objectives and establishing a structure and context for social change. The emphasis in tactical activity is on agenda and coalition building on the sub-system level, and on negotiations among stakeholders and actors. The focus on the operational level is on experimentation, project building and implementation, and more specifically on learning and the co-production of knowledge in the short term. Reflexive activity involves evaluating and assessing the current situation on various levels.

The theory of multilevel socio-technical transition has been successfully applied in many cases across various sectors, but it has also attracted criticism. Berkhout et al. (2004) criticise the emphasis on bottom-up at the cost of top-down activities: although experiments are crucial in the process, there is no less urgency in transitioning the whole system. It must also be acknowledged that not all emerging experiments are viable or prove to be sustainable. Therefore, careful analysis of practical examples and experiments constitutes a good basis on which to design and adapt policy frameworks in line with the recognised barriers and opportunities.

\section{Methods}

This study is based on a close monitoring of the transition to sustainability in the University of Helsinki. The authors were involved in the meetings and in the planning of new 
sustainability activities between 2014 and 2018 . The material for the study consists of planning documents, research profiling applications, descriptions of Bachelor's and Master's degree programmes, and annual review documents (see Table 1).

The first part of the analysis comprises the SDG mapping of key documents depicting the processes of sustainability transition in the university during years 2015-2018. The choice of documents for the analysis reflected the aim to shed light on current developments in the main tasks of the university: research, education and societal activities and its internal operations.

We analysed research profiling applications because they represent new initiatives that cross current faculty borders and existing administrative structures, or strengthen existing research foci. The Ministry of Education and Culture and the Ministry of Economic Affairs and Employment in Finland drafted a policy action programme for research and innovation in 2012, following which the Finnish Government agreed on a crucial strategic decision. This resulted in the creation of a new, targeted funding instrument to strengthen the research profiles of Finnish universities. The Government's public finances plan for the years 2015-2018 earmarked 50 million euros of central government finances for universities, to be allocated through the Academy of Finland over the time period 20152019. These funds were dedicated in their entirety to strengthening the research profiles of universities (Academy of Finland 2018).

Similarly, we analysed the newly established Bachelor's and Master's degree programmes that cross traditional current and rigid disciplinary and faculty borders. These new crossfaculty programmes were established in connection with the educational reform at the University of Helsinki that was initiated in 2015, and have been operational since August 2017. The traditional current educational structure based on separate and independent disciplines offering major subjects in the university curriculum was replaced with broader degree programmes incorporating several disciplines. In total, 15 programmes were classified as crossing faculty boarders and were therefore included in the SDG mapping analysis.

We analysed the actions and operations of the university using the annual review reports for the years 2016-2018. These reports highlight the main attainments, developments and novel initiatives of the reporting year. We excluded the sections dealing with research and education, having analysed new developments in these areas using the more focused and relevant material described above, and used the remaining sections in our analysis of actions and operations. The titles of the sections varied from year to year, but the contents comprised an introduction by the rector, a review of changes in the operating environment (including achievements in university rankings), and sections on social responsibility and public engagement, staff and $\mathrm{HR}$, finances, services and facilities.

All the documents were analysed in line with the SDG framework as follows. The new developments within the university were not planned and designed from the perspective of implementing SDGs, which are not explicitly mentioned in them. Thus, the quantitative 
analysis is based on a qualitative interpretation of the materials using the SDGs and their descriptions and sub-targets as a framework. When we read the documents we collected and organised direct quotations referring to distinct SDGs. On the level of individual profiling areas, degree programmes and annual review reports, we determined the occurrence of each SDG and formed a quantitative aggregate by a grouping them in fourtier categories. We followed this with a further qualitative analysis. We added a qualitative weighting to stress the relative differences in importance of the respective SDGs in these categories by raising its category level by one. For example, SDG 10 is included in four profiling areas, but given that one of them is entirely devoted to inequalities (INEQ), we stressed its qualitative weight. Differences in the number of mentions as well as in the qualitative weighing are indicated in Figure 1 by the relative size of the white circles. We used the framework presented in Getting started with SDGs in Universities - guide (SDSN - Australia/Pacific, 2017) to identify and group management operations and activities, as well as organisational policies linked to sustainability and presented in the annual review reports.

In addition to SDG mapping, we identified factors enabling and restricting the transition through a qualitative analysis of the planning documents supplemented with our notes from the observations in the planning processes and the changes happening in the policy landscape of Finnish science and education. We used this information to interpret the transition initiatives.

Table 1. A summary of the research material

\begin{tabular}{|c|c|c|c|c|}
\hline $\begin{array}{l}\text { Type of } \\
\text { material }\end{array}$ & Description & $\begin{array}{l}\text { Years } \\
\text { covered }\end{array}$ & Remarks & Sources \\
\hline $\begin{array}{l}\text { Research-profiling } \\
\text { applications of the } \\
\text { University of Helsinki } \\
\text { submitted to the } \\
\text { Academy of Finland }\end{array}$ & $\begin{array}{l}\text { Four application documents, a } \\
\text { total of } 129 \text { pages, with } 14 \\
\text { distinct research-profiling } \\
\text { areas described. All the } \\
\text { documents describe how the } \\
\text { respective profiling aligns with } \\
\text { the University's strategy, and } \\
\text { what division of foci among } \\
\text { other national institutions of } \\
\text { higher education are included. }\end{array}$ & $2015-2017$ & $\begin{array}{l}\text { The applications } \\
\text { vary in extent and } \\
\text { the depth at which } \\
\text { the different } \\
\text { profiling actions } \\
\text { are described. }\end{array}$ & $\begin{array}{l}\text { Profiling applications are } \\
\text { not public documents. }\end{array}$ \\
\hline $\begin{array}{l}\text { Descriptions: an } \\
\text { overview of the } \\
\text { curricula of the novel } \\
\text { Bachelor's and } \\
\text { Master's } \\
\text { programmes at the } \\
\text { University of Helsinki } \\
\text { that cross faculty } \\
\text { boarders }\end{array}$ & $\begin{array}{l}\text { Fifteen programme } \\
\text { descriptions, in total } 72 \text { pages } \\
\text { when converted to a Word } \\
\text { document. } \\
\text { All the descriptions include the } \\
\text { following subsections: Study } \\
\text { objectives, Study contents, } \\
\text { Choosing a main subject or } \\
\text { field of specialization, Tuition }\end{array}$ & $\begin{array}{l}2017-2019 \\
\text { Programmes } \\
\text { were } \\
\text { established in } \\
\text { the university- } \\
\text { wide reform of } \\
\text { educational } \\
\text { degree } \\
\text { programmes } \\
\text { and the }\end{array}$ & $\begin{array}{l}\text { The descriptions } \\
\text { vary in extent and } \\
\text { depth, the word } \\
\text { count of each } \\
\text { programme } \\
\text { ranging from } \\
\text { around } 1,000 \text { to } \\
\text { well over } 3,000 \text {. }\end{array}$ & $\begin{array}{l}\text { Information retrieved from } \\
\text { Study.info.fi } \\
\text { in January } 2019 . \\
\text { Studyinfo.fi provides } \\
\text { official and up-to-date } \\
\text { information about study } \\
\text { programmes leading to a }\end{array}$ \\
\hline
\end{tabular}




\begin{tabular}{|c|c|c|c|c|}
\hline & $\begin{array}{l}\text { fees, Structure of studies, } \\
\text { Final project, Career } \\
\text { opportunities, } \\
\text { Internationalization, Co- } \\
\text { operation with other parties, } \\
\text { research focus, Post-graduate } \\
\text { study opportunities }\end{array}$ & $\begin{array}{l}\text { curricula } \\
\text { approved for } \\
\text { the period } \\
2017-2020\end{array}$ & $\begin{array}{l}\text { Only the UH } \\
\text { degree } \\
\text { programmes that } \\
\text { cross faculty } \\
\text { borders were } \\
\text { included in the } \\
\text { analysis }\end{array}$ & $\begin{array}{l}\text { degree in Finland. } \\
\text { Studyinfo 2019a. }\end{array}$ \\
\hline $\begin{array}{l}\text { University of Helsinki } \\
\text { Annual Review } \\
\text { documents. }\end{array}$ & $\begin{array}{l}\text { Annual Reviews comprise the } \\
\text { topics: introduction by the } \\
\text { rector, research, teaching, } \\
\text { public engagement, staff, } \\
\text { finances, services and } \\
\text { facilities. The average length } \\
\text { is } 70 \text { pages. } \\
\text { We omitted the sections } \\
\text { Research and Teaching from } \\
\text { our analysis because these } \\
\text { topics are covered separately } \\
\text { in the more detailed analysis } \\
\text { of research applications and } \\
\text { novel degree programmes } \\
\text { (see above). }\end{array}$ & $2016-2018$ & $\begin{array}{l}\text { In analysing the } \\
\text { years } 2016 \text { and } \\
2017 \text { we used the } \\
\text { annual reviews } \\
\text { published on } 29 \\
\text { March } 2017 \text { and } \\
28 \text { March } 2018 \text {, } \\
\text { respectively. We } \\
\text { were provided with } \\
\text { the final draft for } \\
\text { the year } 2018 \\
\text { because the report } \\
\text { was not publicly } \\
\text { available at the } \\
\text { time. }\end{array}$ & $\begin{array}{l}\text { Annual Review } \\
\text { documents } 2016 \text { and } \\
2017 \text { are available at: } \\
\text { https://www.helsinki.fi/s } \\
\text { ites/default/files/atoms/ } \\
\text { files/the_university_of_h } \\
\text { elsinki_annual_review_2 } \\
\text { 017.pdf } \\
\text { https://www.helsinki.fi/s } \\
\text { ites/default/files/atoms/ } \\
\text { files/the_university_of_h } \\
\text { elsinki_annual_review_2 } \\
\text { 016_and_strategy_revie } \\
\text { w_2013-2016.pdf }\end{array}$ \\
\hline
\end{tabular}

\section{Realising SDGs in the University of Helsinki}

\subsection{SDG mapping}

We conducted SDG mapping of the selected University initiatives that represent new openings in the field of research and education, as well as in the university's operations and activities. Figure 1 summarises the findings.

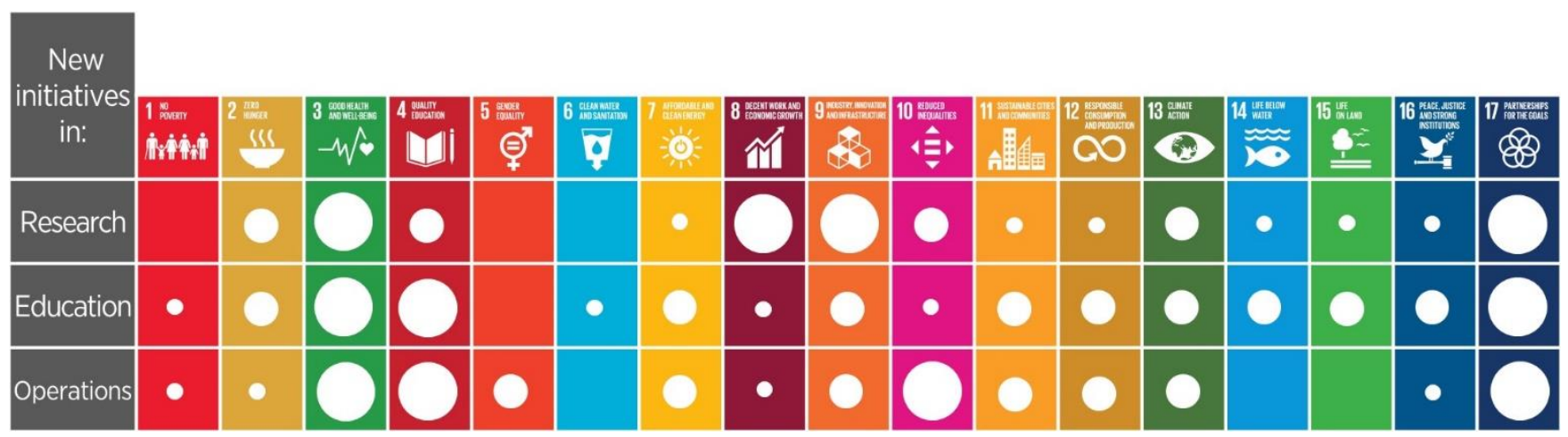

Figure 1. A summary of the SDG mapping of selected documents depicting the transition to sustainability in research (2015-2017), teaching and education (2017-2019), and activities and 
operations (2016-2018) at the University of Helsinki. The size of the circles indicates the frequency of the hits on the particular SDG under consideration: no circle = no hits or only one hit, the smallest circle $=$ a few hits, a medium-sized circle $=$ an intermediate number of hits, and a large circle $=$ several hits.

The analysis of research-profiling activities reveals both obvious and surprising aspects. The fact that SDGs 8, 9, 17 and 3 are the most frequently mapped with regard to new research initiatives reflects the principles of profiling rather than the dominant foci. Given that the application form for profiling funding includes a question about the significance of the profiling and deselections for competence-based growth or other societal benefit, it is obvious that almost all the applications mention this as one of the core elements of success. Additionally, in that the profiling of research is based on the principle of strong national and international collaboration with relevant partners, SDG 17 is inherently included in all the applications. Quality Education (SDG 4) is mentioned in 10 of the 14 applications, which is hardly surprising given that the analysis concerns an institution of higher education.

We also found that the profiling of research in the University of Helsinki stresses Good Health and Wellbeing (SDG 3) and Industry, Innovation and Infrastructure (SDG 9). Both of these goals are broadly connected to many kinds of research initiatives. 'Wellbeing' as a very general goal in particular is easy to incorporate into various kinds of research. However, the particularly strong emphasis on Health and Wellbeing is evident in the fact that apart from being mentioned in 10 of the 14 applications, one of the profiling areas (OneHealth) is devoted entirely to health-related research. The strong emphasis on Industry, Innovation and Infrastructure could be an indication of the pressure exerted on public universities in light of diminishing funding. A focus on industry and innovation could be perceived as a strategy aimed at securing and increasing research funding. Developing and more effectively utilising diverse research infrastructures are general aims that apply to many kinds of research foci, and thus are rather naturally emphasised along many research paths.

However, four Sustainable Development Goals were rarely, if ever, targeted in the documents: No Poverty (SDG 1), Zero Hunger (SDG 2), Gender Equality (SDG 5) and Clean Water and Sanitation (SDG 6). These are goals that Finland as a country has succeeded in achieving (see Sachs et al. 2018). However, the fact that gender equality is not mentioned in any of the new research initiatives is also surprising. It might be that it is implicitly included in the more general mentions of inequality, which in the analysis is included in SDG 10 (Reduced Inequalities).

Of the remaining intermediate categories, the largest one comprises SDGs that are included in between two and five profiling applications of the total 14. This is not surprising, in that the very idea of profiling is to choose different, distinct and complementary core areas of research. Similarly, the inclusion of Clean and Affordable Energy in only two profiling areas stems from the profiling principle of decreasing national overlap in research foci: the area is largely covered by two other Finnish universities (Aalto University and LUT 
University) and is thus not as prevalent in the UH agenda. One profiling area, namely sustainability science and the related establishment of the Helsinki Institute of Sustainability Science (HELSUS), is a significant and recent transition towards a focus on SDG-relevant research at the University of Helsinki. Inherent in this profiling is an emphasis on various SDGs, but the overall range that will be covered within the related research remains to be analysed in the longer term.

Contrary to the analysis of research-profiling areas, mapping related to SDGs in degree programmes fell within the upper-intermediate level of hits. This means that several SDGs could be identified from multiple descriptions of degree programmes. This is quite understandable: $\mathrm{UH}$ profiling areas are meant to target rather than to span, whereas degree programmes crossing faculty borders may include elements related to various SDGs. However, the inventory also identified a large variation among the programmes: some were linked to only one or two goals, and even then quite vaguely, whereas others spanned most of the 17 goals. Although not developed with the SDG framework, courses of study such as the MSc in Environmental Change and Global Sustainability and the Bachelor's programme in the Environmental Sciences were, according to the descriptions, aimed at tackling sustainability challenges within a wide spectrum encompassing almost all the SDGs. In addition, some programmes focused on one or two SDGs in particular. By way of an example, the MSc in Urban Studies and Planning (USP) highlights Goal 11 (Sustainable Cities and Communities), whereas the Master's programme in Human Nutrition and Food-Related Behaviour (HNFB) specifically targets SDG 3 (Good Health and Wellbeing).

Our analysis of SDGs in university education reveals a generally strong emphasis on SDG 3 (Good Health and Wellbeing). Three individual degree programmes targeted these themes in particular, but related themes could also be identified in other BSc and MSc programmes. This could be attributable to the university's long tradition in focusing on health and medicine, as well as to the ideals of the Finnish welfare society emphasising wellbeing as such. A similar emphasis on health and wellbeing has also been identified in some Sustainability Course Inventories (SCls) (see e.g., Brugmann et al. 2019). The minimal emphasis on SDG 1 (No Poverty) was in accord with the results of a similar study conducted in Spain (Albareda-Tiana et al. 2018).

Of the 17 goals, SDG 17 (Partnerships for the Goals) and SDG 4 (Quality Education) were also among those with the most hits related to the educational programmes. This could be considered unsurprising for various reasons. First, given that the description used in the Study.info-platform includes a mandatory section on Co-operation with other parties, almost all the programmes (13/15) met the criteria for SDG 17 (Partnerships for the Goals). Second, all the BSc and MSc programmes included in the inventory were deemed naturally to target SDG4 (Quality Education), having their origins and aims in providing high-quality university teaching. Thus, it could be claimed that this finding reflects both the principles of this particular mapping and the used data set, as well as the emphasis on these SDGs in UH degrees. This is further highlighted when the degree programmes are considered in the wider context of university transformation. One of the big changes that 
occurred simultaneously with the degree reform was the introduction of tuition fees in Finnish universities. Implemented on 1 August 2017, the reform introduced mandatory tuition fees for non-EU/EEA nationals taking international Master's programmes. Given the emphasis in SDG 4 on equal opportunities in education, this change could be seen as counteracting it in spirit and aims.

A similar difference in spirit would seem to affect the fulfilment of SDG 17 (Partnerships for the Goals). Many of the MSc and BSc programme descriptions emphasise cooperation within the University of Helsinki, regionally or within Finland. International possibilities were often generally mentioned in another mandatory section, "Internalization", which includes information on internships and exchange studies. Thus, one might ask if emphasising national strategic partnerships is in line with the spirit of SDG17, which highlights international cooperation, and especially North-South or triangular partnerships, which as such are non-existent in the descriptions. These questions support the choice of some HEls to leave SDG 17 out of the inventories on account of its ambivalent nature (see e.g., Brugmann et al., 2019).

As with research, SDG 5 (Gender Equality) was not mentioned in any of Helsinki University's degree programmes in the mapping of education. This could be attributable in part to the general nature of the analysed texts: paragraphs and sentences highlighting lower levels of inequality in general (linked to SGD 10, Reduced Inequalities) included mentions that also quite likely referred to the study of inequalities related to gender. This also highlights the interconnectedness of the 17 goals.

The mapping does not consider the curriculum in detail, nor its implementation, and therefore does not take into account how the identified themes are acted upon. The general nature of this mapping highlights the need for further research into course content, which could be carried out with existing sustainability-assessment tools such as AASHE's Sustainability Tracking, Assessment and Rating System (STARS) (see, e.g., Maragakis and Dobbelsteen, 2015). This would not only better enable comparison between the University of Helsinki and other HEls, it would also facilitate temporal monitoring within the university, which in turn would foster further discussion on the direction and time-span of desired changes. Although it might be hard to point out the desired high point or culmination of sustainability transition, monitoring and further target setting would help to guarantee continuation in the desired direction.

In terms of the University's own operations and actions, the strongest contributions are directed to advancing quality education (SDG 4), good health and well-being (SDG 3), reducing inequalities (SDG 10) as well as partnerships (SDG 17).

The upper cluster of SDGs implemented in university societal actions and campus operations include those aimed at reducing inequalities. The University of Helsinki has an established committee for promoting and assessing equality, and regularly runs several campaigns. Measures focused on promoting good health and well-being (SDG 3) and providing decent work (SDG 8) include improving workplace wellbeing and healthcare services, and providing re-location services for newly recruited staff members and their 
families. Improvements targeted at advancing quality education include retrofitting equipment for digital on-line teaching, ensuring Open University teaching and science events for the general public and strategic measures to improve degree programmes, student selection and pedagogical competences of teachers. The university also reports strong progress in strengthening and establishing new partnerships (SDG 17) such as with national research institutes, which operate in university premises and collaborate closely with the university both in the research projects and in using joint research infrastructures. New partnerships are also being established with industries and decision makers to promote knowledge transfer and co-creation.

Achievements in improving energy and water efficiency, as well as sustainable production and consumption, mainly concern reducing the consumption of energy, electricity and water, which is also connected to the target of reducing the net floor area in use. Several actions have been taken to increase the output of renewable energy, including its production at the solar power plant on the Viikki campus and the wood chip power plant at Lammi biological station. Solar energy production is expected to represent between five and six per cent of overall annual consumption on the Viikki campus, which has an energyintensive research infrastructure. Other measures aimed at implementing SDGs 7, 12 and 13, which have an environmental and climate action focus include reducing energy and water consumption in buildings by developing energy-efficient solutions and technical systems, supporting sustainable construction projects such as the LEED-certified Kaisa Library Building and the Green Office environmental programme on the Viikki campus, and the launching of a programme to advance healthy and sustainable forms of commuting. In addition, UH has a fair-trade certification and is committed to considering aspects of fair trade in its operations.

However, we found only a few new initiatives targeted at eradicating poverty and hunger, or safeguarding life on land and below water on the level of societal actions or university operations. One explanation for this could be the strong focus on and expertise in technical development, such as the creation of technical solutions for energy, electricity and water supply.

In sum, there is a strong focus on quality education in all the analysed areas, such as in research proposals, new degree programmes, societal activities and university operations. This indicates the existence of well-established links to top educators active in research, active and consistent pedagogical curriculum development, and high standards in teaching and learning facilities, including up-to-date information and communication technologies. The paucity of hits on SDGs 1 (No Poverty), 6 (Clean Water and Sanitation) and 5 (Gender Inequality) was surprising given the university's goal to address global challenges.

The aim in the following analysis is to identify the factors that either enabled or hindered the transition to sustainability in the University of Helsinki. 


\subsection{The internal push for sustainability: active grassroots actors and networks}

A large volume of research linked to sustainability has been conducted at the University of Helsinki in recent decades. Some of it has been carried out within established interdisciplinary networks and centres operating across faculty borderlines. Indeed, there is a long tradition of interdisciplinary cooperation in the field of environmental research. The Helsinki University Environmental Research Unit (HERU) was established in 2002, for example. The name was changed to HERC - Helsinki University Center for Environmental Research, and until 2008 the centre was active in initiating interdisciplinary environmental research in six faculties. Eventually, the multidisciplinary environmental teaching initiative was incorporated into it and together they formed the Helsinki University Centre for Environment, HENVI, which was responsible for carrying out and coordinating environmental research and teaching. All HU faculties contributed to the activities of HENVI, which was successful in creating networks of researchers from different disciplinary backgrounds. The experience gained in HENVI regarding the challenges and opportunities of interdisciplinary collaboration, and the academic networks created, played a crucial role in the later development of the Helsinki Institute of Sustainability Science. The Institute promotes sustainability research, and supports the development of new degree programmes in environmental studies and sustainability science as well as other activities promoting the transition to sustainability in the university.

Helsinki University has also hosted several thematic networks of sustainability research: The University of Helsinki Global South Network (HUGS) concentrates on research and teaching on the Global South, whereas interdisciplinary urban research and teaching are tackled within the Urban Academy and the Helsinki Metropolitan Region Urban Research Programme.

Complementing these formal interdisciplinary networks are several informal networks established among researchers in areas such as environmental archaeology, sustainability and business, as well as the pharmacists' going-green initiative the Generation Green Team. The active role played by a few individual researchers within these networks in creating spaces for interdisciplinary collaboration was also crucial in enabling the later reforms.

In the field of education, Helsinki University's decision to re-structure both Bachelor's and Master's educational programmes facilitated the creation of novel sustainability approaches. The reform was initiated in 2015 and the new degree programmes were operational from August 2017. The current educational structure based on separate and independent disciplines organised as major university subjects in the curriculum was transformed into broader degree programmes involving several disciplines. The reform was conducted under the supervision of the Academic Affairs Council, which defined the general principles of the degree programmes in a meeting held in October 2015. Primarily, the educational overhaul should facilitate the provision of high-quality degree programmes 
that would appeal to applicants and have a broad disciplinary scope enabling students to choose their specialisation later on in their studies. Second, the curriculum should be competence-based, highlighting career-relevant competences, and third, the focus should be on collaboration among teachers and academic disciplines implemented in the form of multi- and inter-disciplinary teaching. In contrast to the current curriculum comprising a major subject and one of several minor subjects, the re-structured Bachelor's and Master's programmes were intended to encompass one or several fields of science, disciplines or thematic modules, and accordingly the faculties were asked to involve a large group of relevant parties from various disciplines, faculties and units in setting them up.

We claim that the educational reform created a window of opportunity for the planning of new degree programmes. Strong and functional teachers' networks in environmental studies, urban studies, sustainability science and several other transdisciplinary areas were activated and embarked on the negotiation and planning of degree programmes and curricula that incorporated current disciplinary approaches into interdisciplinary and novel degree structures.

The strong pressure from environmentally aware students has also led to improvements in university operations and the development of environmentally- and sustainabilityoriented courses and degree programmes. The sustainability- science oriented MSc programme has attracted the most applications since the reforms were introduced.

Furthermore, grassroots-level actors have played a key role in pushing for sustainabilityfocused reforms: for example, one person with a mission to think green and promote renewables and environmental awareness came up with the idea and initiated the process of establishing a solar power plant on the Viikki campus. Such grassroots efforts could be considered tactical and operational-level activities (Graham \& Stephen 2010) in the transition to sustainability in the university - building an agenda and coalitions to push for reforms as well as initiating sustainability projects.

\subsection{External pushing for sustainability: policies and funding}

Complementing the internal activism, the reforms in Finnish science and research policy created a window of opportunity on the regime level.

The funding scheme described above forced universities to strengthen their research profiles and to identify the areas in which they wanted to focus and profile themselves. As Finland's largest and oldest university, the University of Helsinki has a unique position in the country. It covers almost all research fields with the exceptions of technology and business. Defining its future profiling areas and, on the other hand, deciding which areas to deselect to safeguard resources, was a hard exercise for the old, multidisciplinary university. Profiling areas include existing high-quality areas, emerging areas with toplevel potential and new areas with high potential (Academy of Finland 2018).

The University of Helsinki made the strategic decision to add sustainability science as a new emergent area with high potential to its established and strong research fields such as health, atmospherics and data sciences. 
This decision, as well as the successful funding application submitted jointly to the Academy of Finland by six faculties, formed the financial and organisational basis for the Helsinki Institute of Sustainability Science. The funding allowed the establishment of ten new tenure-track professorships, among other positions. Given the size of the country, and of its academia, this is a remarkable number of new research posts. The Academy of Finland will help to fund these professorships for a four-year period, after which time they will be funded by the participating faculties. In other words, the faculties will have to redirect existing resources to these newly established positions, having made the strategic decision to participate in the sustainability science initiative. This directly reflects the strategic-level activities in the transition to sustainability mentioned by Graham \& Stephen (2010). Furthermore, this initiative will change the structures - new interdisciplinary professorships will replace the old faculty Chairs. A similar procedure applies in the other profiling areas, but the focus on sustainability science is specific to the transition to sustainability.

Reform in the field of education was initiated by the university, but there was strong external pressure to renew the degree programmes and structures in light of the increasing competition in educational markets - namely attracting the best international students.

In terms of sustainable operations and actions, the increasing pressure to provide environmentally friendly and energy-efficient premises to tenants in university-owned properties has fuelled investments in new technical solutions. In addition, the national strategy was reformed in 2013 and Society's Commitment to Sustainable Development was established as the key instrument for implementing the UN Agenda for Sustainable Development. Soon after this, in April 2014, the Ministry of Education and Culture sent all Finnish universities a letter of instruction dealing with performance management and annual reporting, with a section on how to submit their strategies for advancing sustainable development in their tasks and actions. This prompted the University of Helsinki to establish a committee for corporate social responsibility. The group prepared the ground and the university made its sustainability pledge in 2015. It undertook to promote the more efficient use of water and energy, healthy and sustainable forms of workplace travel and the development of renewable energy. PhD education would also be tailored more to society's needs, which committed the university to connect its doctoral graduates with the working world. These commitments reflect the established and strong focus on SDGs 3 , $6,7,8$ and 11 , which is reflected in our analysis.

\subsection{External pushing for sustainability: timing}

One of the major factors that enabled the faculty deans to make the crucial strategic decision to focus on sustainability science as well as other initiatives was the obvious urgency (or the lack of it) of sustainability as a real-world challenge to which Helsinki University needed to respond. It had defined sustainability as among the grand challenges 
of the era, as was stated in its strategy. Furthermore, Sustainable Development Goals (SDGs) were set in 2015, and it became clear that countries such as Finland also needed to meet them.

\subsection{Hindering the transition to sustainability: resistance from current disciplines and the faculty structure}

Counteracting the various enabling factors that pushed for the transition to sustainability were several hindering factors that, in the main, related to existing university structures. Sustainability was viewed not as a science as such, but rather as an activity of social interaction with its strong emphasis on transdisciplinary knowledge co-production. Furthermore, the sustainability transformation as an aim and as approach for a new institute of sustainability science was considered too radical and political. This could be referred to as ideological resistance. Reciprocal prejudices concerning the essence of sustainability science were also evident among representatives of different scientific traditions: some social scientists saw it purely as a natural and environmental question, whereas some natural scientists claimed that it was social science devoid of strict scientific methodology. However, these views could be seen as reactions to the perceived risks involved in the profiling activities and the anticipated result of ultimately eliminating some of the established Faculty Chairs.

Experiences from earlier interdisciplinary activities also show that not all scientists are comfortable with inter- and trans-disciplinary activities. This is something that has to be accepted.

It was not only the ideological and epistemological differences and emotional resistance that complicated the organisation of interdisciplinary cross-faculty activities in both research and education: the faculty structure also proved to be a hurdle. The University of Helsinki has a very strong vertical structure - a rectorate and faculties organised according to disciplines, with a few independent units responsible for specific activities or research areas (such as biotechnology). However, these units have a very minor role in teaching activities. A new "joint action unit" linking the faculties was therefore created for the sustainability science centre. The benefit of this kind of structure is that, as formally attached to them, it engages the faculties in the activities of the sustainability science institute.

Cross-faculty degree programmes also face the same difficulties in the field of education in that they operate in an undetermined space from the administrative and financial perspective. Although each degree programme is administratively assigned to one faculty, there are some unclear and undetermined decision processes and allocations of financial resources. As with the hindering factors distinguished in the transition to sustainability, ideological and epistemological differences as well as emotional resistance also play a role in the educational arenas. Cross-faculty degree programmes encounter resistance 
from teachers who value mono-disciplinary structures and research. The same pattern was observed in university operations and activities as problems with working across administrative lines arose in the planning and implementation of new sustainability initiatives.

In short, our analysis supports the results of previous studies on implementing SDGs in universities implying that whole-institution approaches are essential in the transition to sustainability (Muller-Christ et al., 2014; Albareda-Tiana et al. 2018). Mori Junior et al. (2019) further conclude that universities are at the forefront in implementing SDGs, particularly in terms of educating leaders of the next generation. They also point out that the transition to sustainability requires the commitment of the leadership - which was also confirmed in our study.

\section{Conclusions}

The results of the SDG mapping in the University of Helsinki show that Quality Education (SDG 4) is the goal that is clearly important for all the new initiatives in research, teaching and in its own operations. In addition, SDG 17 (Partnerships) and SDG 3 (Health and Wellbeing) are also strongly emphasised in all the initiatives. On the other hand, SDG 1 (No Poverty), SDG 6 (Clean Water and Sanitation) and SDG 5 (Gender Equality) are not considered, or are given little emphasis. This raises questions about the university's commitment to global development on the strategic level: surely these aspects should be covered in its new strategic planning if the aim is to have a global impact.

The Times Higher Education (THE) University Ranking focuses on 11 SDGs, excluding SDG 1 (No Poverty) SDG 2 (Zero Hunger), SDG 7 (Clean Energy) SDG 6 (Clean Water and Sanitation) SDG 15 (Life on Land), and SDG 14 (Life Below Water). This focus was decided following consultation with HEls (THE 2019). However, our analysis shows that universities could play a significant role in making use of new energy solutions (such as solar panels).

To conclude, the transition to sustainability is a complex process involving various actors and interests. If one considers the renewal processes that enabled such transition in the University of Helsinki in light of transition theory (Geels and Shot 2007), one could indeed conclude that small niche innovations, tactical and operational activities on the grassroots level, networks, science activism and student awareness pushed for regime-level changes. However, the financial incentives and policy changes initiated on the regime level facilitated niche-level innovations and led to the making of strategic decisions providing a window of opportunity for the initiation of structural changes. This transition enabled the university to take an active role in solving sustainability problems and implementing Sustainable Development Goals (SGDs) on the societal level. 


\section{References}

Academy of Finland. (2018). Competitive funding to strengthen university research profiles. Retrieved 26 June 2018, from https://www.aka.fi/en/research-and-sciencepolicy/university-profiling/

Albareda-Tiana, S., Vidal-Raméntol, S., \& Fernández-Morilla, M., (2018). Implementing the sustainable development goals at University level. International Journal of Sustainability in Higher Education, 19(3), 473-497. doi: 10.1108/IJSHE-05-2017-0069

Barth, B., \& Michelsen, G. (2013). Learning for change: an educational contribution to sustainability science Sustain. Sci., 8, 103-119.

Beringer, A. \& Adomßent, M. (2008). Sustainable university research and development: inspecting sustainability in higher education research. Environmental Education Research, 14(6), 607-623. doi: 10.1080/13504620802464866

Berkhout, F., Smith, A. \& Stirling, A. (2004). Socio-technological regimes and transition contexts. In System Innovation and the Transition to Sustainability: Theory, Evidence and Policy; Elzen, B., Geels, F.W., Green, K., Eds.; Edward Elgar: Cheltenham, UK, 48-75.

Beynaghi, G., Trencher, F., Moztarzadeh, M., Mozafari, R., Maknoon, W. \& Leal Filho. (2016). Future sustainability scenarios for universities: moving beyond the United Nations decade of education for sustainable development. J. Clean. Prod., 112. 1464-1474.

Brugmann, R., Côté, N., Postma, N., Shaw, E.A., Pal, D. \& Robinson, J.B. (2019). Expanding Student Engagement in Sustainability: Using SDG- and CEL-Focused Inventories to Transform Curriculum at the University of Toronto. Sustainability 2019, 11, 530.

Bulkeley, H. \& Castán Broto, V. (2012). Government by experiment? Global cities and the governing of climate change. Trans. Inst. Br. Geogr., 38, 361-375

Dedeurwaerdere, T. (2013). "Transdisciplinary sustainability science at higher education institutions: science policy tools for incremental institutional change" Sustainability, 5, 3783-3801.

Ferrer-Balas, D., Adachi, J., Banas, S., Davidson, C.I., Hoshikoshi, A., Mishra, A., Motodoa, Y., Onga, M. \& Ostwald, M. (2008). An international comparative analysis of sustainability transformation across seven universities. Int. J. Sustain. High. Educ., 9(3), 295-316.

Ferrer-Balas, D., Buckland, H., \& de Mingo, M. (2009). Explorations on the University's role in society for sustainable development through a systems transition approach. CaseStudy of the Technical University of Catalonia (UPC). J. Clean. Prod., 17, 1075-1085. 
Findler, F., Schönherr, N., Lozano, R., Reider, D., \& Martinuzzi, A. (2019). The impacts of higher education institutions on sustainable development: A review and conceptualization. International Journal of Sustainability in Higher Education, 20(1), 2338. doi:10.1108/IJSHE-07-2017-0114

Geels, F.W. (2002). Technological transitions as evolutionary reconfiguration processes: a multi-level perspective and a case-study. Res. Policy, 31, 1257-1274.

Geels, F.W., \& Schot J. (2007). Typology of sociotechnical transition pathways. Res. Policy, 36, 399-417.

Holmberg, J. \& Samuelsson, B. (Eds). (2006). Drivers and Barriers for Implementing Sustainable Development in Higher Education. Unesco, Paris, 7-11. Available at: http://unesdoc.unesco.org/images/0014/001484/148466E.pdf

Loorbach, D. (2007). Transition management: New mode of governance for sustainable development. PhD Thesis. Erasmus University Rotterdam.

Lozano, R., Ceulemans, K., Alonso-Almeida, M., Huisingh, D., Lozano, F.J., Waas, T., Lambrechts, W., Lukman, R., \& Huge J. (2015). A review of commitment and implementation of sustainable development in higher education: results from a worldwide survey. J. Clean. Prod., 108, 1-18.

Maragakis, A. \& Dobbelsteen, A. (2015). Sustainability in Higher Education Analysis and Selection of Assessment Systems. Journal of Sustainable Development, Vol. 8, 3.

Mori Junior, R., Fien, J., \& Horne, R. (2019) Implementing the UN SDGs in Universities: Challenges, Opportunities, and Lessons Learned. Sustainability: http://doi.org/10.1089/sus.2019.0004

Müller-Christ, G., Sterling, S., van Dam-Mieras, R., Adomßent, M., Fischer, D. and Rieckmann, M. (2014),"The role of campus, curriculum, and community in higher education for sustainable development -a conference report Journal of Cleaner Production, Vol. 62, pp. 134-137. 
Sachs, J., Schmidt-Traub, G., Kroll, C., Lafortune, G., \& Fuller, G. (2018). SDG Index and Dashboards Report 2018. New York: Bertelsmann Stiftung and Sustainable Development Solutions Network (SDSN).

SDSN Australia/Pacific (2017). Getting started with the SDGs in universities: A guide for universities, higher education institutions, and the academic sector. Australia, New Zealand and Pacific Edition. Sustainable Development Solutions NetworkAustralia/Pacific, Melbourne. Retrieved 14 March 2019, from: http://apunsdsn.org/regional-initiatives/universities-sdgs/university-sdg-guide/

Soini, K., Jurgilevich, A., Pietikäinen, J. \& Korhonen-Kurki, K. (2018). Universities responding to the call for sustainability: A typology of sustainability centres. J. Clean. Prod., 170C: $1423-1432$.

Stephen, C., \& Graham A.C. (2010). Toward an empirical research agenda for sustainability in higher education: exploring the transition management framework. $J$. Clean. Prod., 18, 611-618.

Times Higher Education. (2019). Why universities must work together to achieve Sustainable Development Goals. Retrieved 14 March 2019, from: https://www.timeshighereducation.com/world-university-rankings/why-universities-mustwork-together-achieve-sustainable-development-goals

Trencher, G., Yarime, M., McCormick, K., Doll, C., Kraines, S., \& Kharrazi, A. (2014). Beyond the third mission: exploring the emerging university function of co-creation for sustainability. Sci. Publ. Pol, 41(2), 151-179. 